\title{
Ercilla y la Poesía Mexicana
}

$\mathrm{N}$ México las huellas de Ercilla empiezan a notarse casi
en losores de la literatura colonial. Francisco de Terrazas, poeta que floreció a fines del siglo dieciséis, da claros indicios de haber sido muy aficionado a la lectura de $L a$ Araucana. Los pocos fragmentos conservados de su poema épico, Nueno mundo y conquista, abundan en reminiscencias ercillanas. Ya observó Menéndez y Pelayo que el episodio central del poema, la intriga amorosa de Huitzel y Quetzal, está inspirado en las ficciones poéticas de Ercilla. En efecto, los amantes de Terrazas, como los de Ercilla, no son indios humildes sino hijos de reyes o caciques; los españoles son culpables de la tragedia que les aflige; y ambos poetas se empeñan en presentar a las mujeres indígenas tan enamoradas que ni la cautividad ni la muerte las aterrorizan. Pero no es sólo en el episodio de Huitzel y Quetzal donde Terrazas sigue de cerca los pasos del poeta español. Parece indudable, por ejemplo, que el calachuní o cacique de Cozumel, aquel gran orador convertido al catolicismo por Cortés, ha recibido lecciones de retórica de los labios de Colocolo. Otro indio idealizado a lo Ercilla es Mochocoboc, "prudente, osado y de virtud amigo". Además, la tremenda invectiva lanzada contra los españoles por Huitzel es muy parecida a las que lanzan Galbarino y sus compatriotas en la épica chilena. Como Ercilla, Terrazas no vacila al criticar duramente a los conquistadores por medio de la lengua indígena. A todo esto añádese que el afán de imitar lleva a Terrazas a parafrasear algunos versos de La Araucana: 
No se movió una ceja ni pestaña, Ni un hombre dió ni recogió el aliento. (Terrazas)

Ceja no se movió, y aun el aliento Apenas al espíritu halló vía. (Ercilla)

Cuando del largo baile nuestra suerte

A todos ya cansados los tenía, De nuestra libertad ya descuidados, En vino y grave sueño sepultados... (Terrazas)

$\mathrm{Y}$ pensando tener campo seguro

También a descansar se retiraban, Quedando mudo el fuerte, y los soldados En vino y grave sueño sepultados. (Ercilla)

Otro monumento de la literatura de Nueva España en el cual se advierte el influjo de la épica ercillana es El peregrin! indiano de Antonio Saavedra Guzmán, publicado en Madrid en 1599. El elogio que hace Saavedra Guzmán de los indios de Cozumel trae a la memoria las octavas dedicadas por Ercilla a ensalzar "la sincera bondad y la caricia" de aquella "sencilla gente" mencionada en el canto XXXVI de La Araucana:

Era apacible gente, nunca usada

Al uso militar, guerras ni daño,

Mansa, apacible, honesta, bien mirada,

Sin malicia, doblez, ni mal ni engaño.

La mujer del cacique de Cozumel en El peregrino indiano nos recuerda a Fresia, esposa de Caupolicán, por la vehemencia con que increpa a su pusilánime marido. Es ella, como Fresia en La Araucana, la única figura femenina presentada con verdadero realismo. Los diversos "senados" celebrados en el poema de Saavedra Guzmán son muy semejantes a los que describe Ercilla; fáltales únicamente a los mexicanos la costumbre de la borrachera, de que tanto abusan los araucanos. Casi invariablemente intervienen en dichos "senados" los tres tipos consagrados por Ercilla: el sabio viejo, el caudillo autoritario, y el joven belicoso, representados en La Araucana por Colocolo, Caupolicán y Tucapel, en $E l$ peregrino indiano por Ixayacatzin, Cabalcán y Xami. Tampoco deja Saavedra Guzmán de imitar las ficciones poéticas con que Ercilla rompe la mono- 
tonía de la narración guerrera, si bien el poeta mexicano confiesa que "los casos amorosos" le son "ocultos y embarazosos".

Es de advertir que a veces Saavedra Guzmán, modificando ligeramente la fórmula ercillana, permite que un español se enamore de una india - situación jamás encontrada en $L a$ Araucana. Las heroínas de Saavedra Guzmán -Richarchel, Curaca, Culhua, Xuchitl- son todas hermanas gemelas de las Guacoldas, Tegualdas y Laucas de La Araucana. Y en cuanto a la belleza física las indias mexicanas no ceden en nada por cierto a las araucanas, pues si Guacolda hace alarde de un "pecho blanco", Culhua puede igualmente enorgullecerse de una "frente alabastrina". Prototipo de la hechicera Tlantepuzylama en el poema de Saavedra Guzmán es el gran mago de Ercilla, Fitón. Francisco Pimentel sugiere que el modelo de que se vale Saavedra Guzmán lo surte Tlaxcallan, mago que aparece, en El Bernardo de Bernardo de Balbuena. Pero esto es poco probable, pues $E l$ peregrino indiano se publicó en 1599, El Bernardo en 1624. En cuanto al estilo poético, es evidente que Saavedra Guzmán hace esfuerzos desesperados por seguir la manera enérgica y grandilocuente de Ercilla. Muchas de las comparaciones homéricas -zoológicas en su mayoría - que embellecen el poema de Ercilla se encuentran en El peregrino indiano. Aun trata Saavedra Guzmán de imitar a veces las figuras retóricas menos comunes del poeta español:

Cuales contrarias aguas a toparse

Van con rauda corriente sonorosa

Que, resistiendo al tiempo del mezclarse,

Aquélla más violenta $\mathrm{y}$ poderosa

A la menos pujante sin pararse

Volverla contra el curso es cierta cosa:

Así a nuestro escuadrón forzosamente

Lo arrebató la bárbara corriente. (Ercilla)

Cual dos contrarias aguas muy furiosas, Que con rauda corriente procelosa

En yéndose a juntar, muy poderosas

Vence a la flaca la que es muy furiosa:

$\mathrm{Y}$ sus grandes corrientes poderosas,

Hace volver la débil presurosa, 
Así vuelven de bárbaros cercados

Los valientes hermanos Alvarados. (Saavedra Guzmán)

Aunque menos visible que en las dos obras ya citadas, la influencia de $L a$ Araucana no falta del todo en el poema épico de Gaspar Pérez de Villagrá, Historia de la Nueva México, el cual se dió a luz en Alcalá en 1610. Motivos de sobra tenía este poeta para ser adicto a la obra de Ercilla: el Villagrá o Villagrán que desempeña un papel importantísimo en La Araucana era pariente suyo; además, difícilmente le hubiera escapado al poeta el paralelo entre sus experiencias guerreras en el norte de México y las de Ercilla en el sur de Chile. El influjo de La Araucana en el poema de Pérez de Villagrá se manifiesta principalmente en la retórica rimbombante empleada a cada paso por los Ácomas, en los diversos "senados" por ellos reunidos, y en varios cuentos sentimentales de amantes indígenas. No están ausentes del poema los tres tipos ercillanos ya encontrados en $E l$ peregrino indiano: el papel de Tucapel le corresponde a Zutacapán, el de Colocolo a Chumpo, y el de Caupolicán a Zutancalpo. En la idealización de las mujeres indias Pérez de Villagrá no le va en zaga a Ercilla. A este respecto, baste citar los versos con que Gicombo se despide de Luzcoija :

\footnotetext{
Juro por la belleza de esos ojos, Que son descanso y lumbre de los míos, $\mathrm{Y}$ con aquestos labios con que cubres, Las orientales perlas regaladas, $Y$ por aquestas blandas manos bellas, Que en tan dulce prisión me tienen puesto, Que ya no es posible que me excuse De entrar en la batalla contra España.
}

Existe un paralelo inconfundible entre la ejecución de Tempal y Cotumbo en el poema de Gáspar de Villagrá y la descripción de la muerte de Galbarino y sus compañeros en La Araucana. En ambos poemas los españoles entregan la soga a los indios y luego les mandan que se ahorquen. $\mathrm{Y}$ Tempal, como Galbarino en La Araucana, ya subido al árbol, aprovecha los 
últimos momentos de vida para lanzar una diatriba de exaltada ira contra sus verdugos:

\footnotetext{
Mas de una cosa ciertos os hacemos, Que si volver podemos a vengarnos, Que no parieron madres castellanas, Ni bárbaras tampoco en todo el mundo, Más desdichados hijos que a vosotros.
}

Los demás poemas épicos o históricos del periodo colonial ofrecen pocas semejanzas con La Araucana. Ruiz de León en La Hernandia sigue, en ocasiones casi textualmente, la Historia de la conquista de México de Antonio de Solís. Verdad es que en este poema hay dos guerreros aztecas locamente enamorados, Chiltecpi y Alcaltetepo - personajes que no aparecen en la obra de Antonio de Solís y que tal vez sean reflejos lejanos de los amantes de $L a$ Araucana. En cuanto a otro poema histórico de la época colonial, el México en 1623 de Arias Villalobos, parece probable que el poeta imite la manera brutalmente realista de Ercilla en alguna que otra escena bélica, como en la siguiente, por ejemplo:
Macanas contra espadas se ejercitan, Tajando humanos cuerpos en pedazos;
Ya saltan cabezas, ya palpitan
Vivas entrañas, pechos, piernas, brazos, Donde unos mueren, otros resucitan;
$\mathrm{Y}$ en medio de los muertos, embarazos,
No se oye voz que dé mayor sosiego, Que muerte, rabia, espanto, asombro, y fuego.

Quizás no huelgue notar, además, que el Dios del Lago del poema de Arias Villalobos se asemeja bastante a Fitón, el mago de Ercilla. Los dos hechiceros muestran una extraña familiaridad con la mitología clásica y poseen un cristal en que se desarrollan escenas de la historia de España.

No vuelve a encontrarse el rastro de La Araucana en México sino hasta mediados del siglo diecinueve. En $1851 \quad L a$ Ilustración Mexicana publicó un poema anónimo titulado $\mathrm{Xi}$ coténcatl. Consta de ciento veinte octavas reales y relata có- 
mo Xicoténcatl, rey de Tlaxcala, ya hechas las paces con los conquistadores, es traicionado por un amigo suyo, el cual le acusa de haber tomado parte en una conspiración contra los españoles. Estos matan a Xicoténcatl; y la querida del rey, la hermosa Teutila, cae en poder de cierto vil soldado casteliano, llamado Fernández. Tales como les concibe el poeta anónimo, los tlaxcaltecas son bastante semejantes a los araucanos de Ercilla: denodados, de espíritu independiente y elocuentísimos en el hablar. Nada más ercillano que el "senado" que convocan los tlaxcaltecas:

Xicoténcatl el padre alzó su acento:

Anciano en la virtud encanecido, Aún conservaba el juvenil aliento De la vejez a la prudencia unido; Combate el vil en decoroso intento, Pide que el general más aguerrido Se apreste una falange a alzar ligera $\mathrm{Y}$ defender con ella la frontera.

Sigue la discusión y acalorados Dos sabios respetables senadores Perdieron los estribos e indignados Mutuamente dijéronse primores;

De sus enojos a la furia dados Se olvidan de los públicos temores: Con calma a componerse los cabellos La cuestión por cortar habló uno de ellos:

Concédese permiso al estranjero Para entrar en Tlaxcala: vaya en tanto Con tropas Xicoténcatl, el guerrero, A sembrar en sus filas el espanto, Que asi disculpas hay si el hado fiero Nos reserva derrotas y quebranto. Dijo así el senador con entereza, $\mathrm{Y}$ los demás inclinan la cabeza.

El episodio romántico de Xicoténcatl y Teutila, tan trágicamente terminado, muestra un parentesco indudable con las ficciones poéticas de Ercilla. La malaventurada Teutila, dechado de fidelidad y hermosura, no es otra que la doncella tan- 
tas veces encontrada en las imitaciones coloniales de La Araucana:

\author{
Rosado es su color, breve su huella, \\ Dulce su roz, serena su mirada: \\ EI alba el cielo al aclarar tranquila \\ Es menos hechicera que Teutila.
}

Otro poema del siglo diez y nueve que refleja a las claras la influencia de La Araucana es el Cuauhtémoc de Eduardo del Valle, publicado en 1886. El estilo de Eduardo del Valle está forjado en la fragua de Ercilla y parece indiscutible que los aztecas que presenta el poeta se han educado en la misma escuela que los araucanos. El vocabulario épico de Eduardo del Valle se deriva casi en su totalidad de Ercilla. Como éste, el autor de Cuauhtémoc saca la mayoría de sus símiles del reino zoológico. No se hallan en Cuauhtémoc las ficciones poéticas tan características de La Araucana, pero, por otra parte, tampoco muestra el poeta mexicano mayor realismo que Ercilla al referirse a las indígenas :

No volverán quizás a los fulgores
Que derraman la luna y las estrellas,
A prometer la fe de sus amores
Temblando ruborosas las doncellas.
No volverán ni siervos ni señores
A acariciar las esperanzas bellas,
De hacer que sientan el primer latido
Sus corazones que de amor son nido.

Los guerreros de Eduardo del Valle no son indios sino héroes griegos. No vacila el poeta, pues, en comparar a Cuauhtémoc con Eneas ni en llamar a Tzilacátl "el valeroso Alcides mexicano". Las diversas asambleas convocadas por los aztecas en Cuauhtémoc son reflejo fiel de los "senados" reunidos en La Araucana. En elocuencia y ardor patriótico, por supuesto, los "senadores" aztecas ceden muy poco a sus prototipos ercillanos:

Al oír las contrarias opiniones Que tienen al Consejo dividido, 
Palpitan con afán los corazones

De aquéllos que la guerra han decidido;

$Y$ el joven Cuauhtemoc, cuyas acciones

De héroe la admiración han merecido,

Se yergue con viril atrevimiento

Para expresar su bélico ardimiento.

No es tiempo ya de discutir, la hora

Pasó de escudriñar nuestro destino;

Tócanos sólo resistir ahora

Al invasor que a nuestra patria vino.

La paz que nos propone es red traidora;

Es mentida promesa de asesino

Que desarma a la víctima inocente

Para sacrificarla fácilmente.

¡No haya piedad! Convóquese la guerra

A todo el que en Anáhuac ha nacido;

El pueblo que sus dioses y su tierra

Defiende, es respetado aunque vencido.

¿A quién la muerte en el combate aterra

Si sabe que es la paz el bien perdido?

¡No haya piedad! Gritemos de esta suerte:

¡Tregua a la paz! ¡O salvación o muerte!

La poesía mexicana del período nacional no cuenta con otra imitación de La Araucana comparable al Cuauhtémoc de Eduardo del Valle. Quizás valga la pena, sin embargo, mencionar de paso dos poemas - el uno corto, el otro largo pero trunco- en los que el influjo ercillano es bastante manifiesto. Delicioso remedo del estilo de Ercilla adviértese en las sonoras octavas de "Tlahuicole", poema de Rafael de Zayas Enríquez publicado en la Revista Azul del año de 1894. Pero si Zayas Enríquez supo seguir acertadamente las huellas de Ercilla, a Francisco Galindo Torres, autor de La Quauhtemoida, le ocurrió lo contrario, pues de todas las imitaciones de La Araucana ésta es, sin lugar a dudas, la más desastrosa. Cuatro cantos de este poema se dieron a la publicidad en Zapotlán en 1903, y doce cantos adicionales en Guadalajara en 1912. Punto menos que ininteligible a veces, La Quauhtemoida consiste principalmente en interminables "senados" en los que dan rienda suelta a su talento retórico los oradores mexicanos: 
A las voces alegres $\mathrm{y}$ animadas El llanto sucedió; mas con acento Fuerte habló así Quauhtémotl: "Desgraciadas, Desde el niño hasta el viejo macilento, Serían las criaturas, si, arrastradas Por el dolor, pensaran un momento Como tú hablaste... ¿ Juzgas, buen anciano, Que sólo muere el de cabello cano?

El joven esforzado, la doncella Que heridos son por la terrible muerte ¿Siguen gozando de la luna bella, Del magnífico sol?... Triste la suerte Sería del mortal, que ni su huella Deja en el mundo, si en su cuerpo inerte Todo acabara. Los benignos dioses Tiranos serían y muy feroces.

$\mathrm{Y}$ ¿quién piensa vivir si el estallido Se escucha de las armas invasoras? Bajemos al sepulcro, allí ni el ruido Podrá llegar de huestes opresoras Que pisan este suelo tan querido Y por el cual, Tezcátzin, tanto lloras". Así el Monarca mejicano dijo, $\mathbf{Y}$ el concurso aplaudió con regocijo.

La Quauhtemoida -inútil es decirlo- no merecería mención alguna si no fuera, al parecer, el último reflejo de $L a$ Araucana que se encuentra en la poesía mexicana.

La atracción que sentían por La Aráucana los vates de la Nueva España nada tiene de extraño; ocurrió lo mismo en otros países de América y también en España. Pero, ¿cómo explicar que los poetas del período nacional sintiesen la misma atracción? ¿Será que simpatizaban con la actitud de Ercilla frente al indio? \&O es que echaban de menos en la literatura patria una obra que pudiera competir con la épica chilena?

\author{
DANIEL WOGAN, \\ Louisiana State University.
}


